\title{
Analysis of Diversity among Potato Accessions Grown in Eritrea Using Single Linkage Clustering
}

\author{
Biniam Mesfin Ghebreslassie',2, S. Mwangi Githiri², Tadesse Mehari', Remmy W. Kasili3 \\ ${ }^{1}$ Department of Horticulture, Hamelmalo Agricultural College, Keren, Eritrea \\ ${ }^{2}$ Department of Horticulture, Jomo Kenyatta University of Agriculture and Technology, Nairobi, Kenya \\ ${ }^{3}$ Institute of Biotechnology Research, Jomo Kenyatta University of Agriculture and Technology, Nairobi, Kenya \\ Email: bm95913@yahoo.com
}

Received 21 April 2015; accepted 22 August 2015; published 27 August 2015

Copyright (C) 2015 by authors and Scientific Research Publishing Inc.

This work is licensed under the Creative Commons Attribution International License (CC BY). http://creativecommons.org/licenses/by/4.0/

(c) (7) Open Access

\begin{abstract}
Potato is an important cash and food crop, a source of income to many small scale farmers in Eritrea. In the long tradition of potato cultivation farmers have adopted a number of landraces. However, very little is known about their genetic diversity which limits further breeding programs to improve productivity. The objective of the study was to characterize potato accessions grown in Eritrea. A total of 21 accessions collected from farmers and NARI were used in this study for characterization employing 33 phenotypic descriptors. Single linkage (nearest neighbor) clustering method using UPGMA employing Euclidean test was used to yield a dendrogram. The clustering generated three main clusters with further sub clusters. The clustering helped to identify accessions that shared the same characteristics and/or that were closely related and vice versa. It was noted that there was no distinct relationship between the clusters groups and geographic sources of accession. Yet, accessions sharing the same name may not necessarily share the same genetic content. Mean deviation of variables for each group from the total mean indicated that Group III followed by group I showed negative deviation in most of the recorded yield related traits. Group I was particularly affected by the presence of two inferior accessions in the group. On the other hand, Group II accessions showed relatively maximum deviation from the total mean and could be recommended for use as parent for any breeding program in Eritrea.
\end{abstract}

\section{Keywords}

Solanum tuberosum, Potato, Eritrea, Morphological Traits, Cluster, Diversity 


\section{Introduction}

Potato is an important cash and food crop in Eritrea, playing significant role in combating food insecurity. It is grown by small scale farmers mainly in the high land part of the country Zoba Debub and Maekel [1] with limited coverage in Zoba Anseba and Semenawi Kehy Bahri [2]. The estimated land area under potato cultivation is about 2000 ha (Unpublished MoA data) but the yield is below 10t/ha, like most of Eastern African countries [3]. This is not only lower than the world average (16 t/ha) but also low compared to the $25 \mathrm{t} / \mathrm{ha}$ that can be attained by progressive farmers under rainfed conditions [4]. To intervene and thus formulate possible solutions, there is need to gather information on the basic characteristics of the accessions grow in the country. All the potato accessions currently growing in the country are of foreign origin, although farmers have adopted a number of landraces during the long tradition of growing the crop. Some of the landraces, such as carneshim, Yeha, Tsaeda_embaba, Keyh_embaba, shashemanie etc., are selected by the farmers owing to their superiority on yield, taste, maturity, resistance and/or marketability [5]. However, the landrace have not been identified and, therefore, have not been registered. They are merely known by their flower colour and/or the place name where they were imported from. According to [6] landrace cultivars are significant sources of genetic variation. Moreover, understanding variability among the population is not only essential [7] [8], but is also an effective perquisite for a successful breeding program [9]. Such information is lacking for potato accessions in Eritrea hence this study is conducted.

The current study was designed to assess the nature and magnitude of diversity among the potato accessions currently grow in Eritrea using morphological descriptors. The finding will help to understand the similarity and/or diversity among the accessions. The findings will further identify traits contained by each cluster (group), opening door for breeding programs to improve productivity of the crop.

\section{Methodology}

Twenty-one potato accessions (landraces and imported) collected from farmers (Yeha, Tsaeda_embaba_I, Keyh_embaba_I, Tsaeda_embaba_II, Carneshim, Shahemanie_I, Zafira_I, Round_Sudan, Oval_Sudan, Keyh_ embaba_II, Tsaeda_embaba_III, Shashemanie_II, Keyh_embaba_III, Ajeba, Zafira_II, Safira and Grandnain) as well as (Banba, Baren, Orla and Slaney) provided by the National Agricultural Research Institute (NARI) of Eritrea were used in this study. Tuber seeds were allowed to sprout and later planted in two locations under farmers' conditions. The first site was located at the experimental field of Hamelmalo Agricultural College (HAC) with an altitude of about $1330 \mathrm{~m}$ above sea level with 15 '53N and 38'26E coordinates. Since the crop was adapted to cool seasons, planting was purposely done towards the end of winter when the temperature was relatively low. The second site was located in the high land (Asmara) with $2363 \mathrm{~m}$ above sea level altitude and $15 ' 20 \mathrm{~N}$ and 38'56E coordinates. The chemical property of the soil in both sites was analyzed in the soil laboratory of the National Agricultural Research Institute (NARI) Halhale (Table 1).

The experiment was conducted using a randomized complete block design (RCBD) with three replications, 21 plots and 18 plants per plot. Tubers were sown at $70 \mathrm{~cm}$ between rows and $40 \mathrm{~cm}$ between plants. Land preparation was done in December, 2013 with traction followed by manual leveling. Fertilizers in the form of Di-ammonium Phosphate (DAP) at the rate of $200 \mathrm{~kg} / \mathrm{ha}$ at planting and Urea at the rate of $150 \mathrm{~kg} / \mathrm{ha}$ at 30 days after planting were applied. The experimental plots were furrow-irrigated every week (HAC) and every two weeks (ASM).

Table 1. Soil chemical properties of HAC and ASM sites.

\begin{tabular}{|c|c|c|c|c|c|c|c|c|c|c|}
\hline \multirow{2}{*}{ Site } & \multirow{2}{*}{$\begin{array}{l}\text { TN } \\
(\%)\end{array}$} & \multirow{2}{*}{$\begin{array}{c}\mathbf{P} \\
(\mathbf{p p m})\end{array}$} & \multirow{2}{*}{$\begin{array}{l}\text { OM } \\
(\%)\end{array}$} & \multirow{2}{*}{$\begin{array}{c}\text { EC } \\
\mathrm{dS} / \mathrm{cm}\end{array}$} & \multirow{2}{*}{$\mathbf{p H}$} & $\mathrm{Na}$ & Ca & Mg & $\mathbf{K}$ & CEC \\
\hline & & & & & & \multicolumn{5}{|c|}{ Cmol (+)/kg } \\
\hline \multirow[b]{2}{*}{ HAC } & 0.05 & 2.03 & 0.96 & 0.13 & 8.20 & 0.68 & 18 & 5 & 0.18 & 24.9 \\
\hline & $\begin{array}{l}\text { Very } \\
\text { low }\end{array}$ & $\begin{array}{l}\text { Very } \\
\text { low }\end{array}$ & $\begin{array}{l}\text { Very } \\
\text { low }\end{array}$ & $\begin{array}{l}\text { Non } \\
\text { saline }\end{array}$ & $\begin{array}{l}\text { Moderately } \\
\text { alkaline }\end{array}$ & Moderate & High & High & Very low & $\begin{array}{c}\text { Moderate/ } \\
\text { high }\end{array}$ \\
\hline \multirow[b]{2}{*}{ ASM } & 0.03 & 16.2 & 0.52 & 0.77 & 7.8 & 1.2 & 49 & 12 & 0.93 & 64.2 \\
\hline & $\begin{array}{l}\text { Very } \\
\text { low }\end{array}$ & High & $\begin{array}{l}\text { Very } \\
\text { low }\end{array}$ & & $\begin{array}{l}\text { Slightly } \\
\text { alkaline }\end{array}$ & High & High & High & Moderate & High \\
\hline
\end{tabular}


Data on morphological traits were recorded as per the descriptors reported by [10]. The qualitative morphological characters were recorded using numerical codes of (0 to 9), whereas data for quantitative traits were determined by measurement. Data was normalized using coefficient matrix before further multivariate analysis was conducted. Single linkage (nearest neighbor) clustering method using Unweighted Pair-group Method with Arithmetic Averages (UPGMA) employing Euclidean test, was used to yield a dendrogram. In order to observe the value of each group in the cluster, mean deviation of each variable from the grand mean of the quantitative parameters was calculated. Results of all analyses are presented below in the forms of tables, text and figures.

\section{Results and Discussions}

\section{Cluster Analysis}

Cluster analysis is useful for classifying different accessions hierarchically based on their similarity matrix classification [7]. In the current study, cluster analysis based on similarity matrix employing Euclidean test successfully classified the accessions into three clusters (groups) at 92\% similarity level. Group I consists accessions: Yeha, Tsaeda_embaba_II, Shahemanie_I, Tsaeda_embaba_I, Shashemanie_II, Keyh_embaba_II, Keyh_embaba_III and Keyh_embaba_I; Group II consists of: Safira, Banba, Zafira_II, Baren, Slaney, Orla, Zafira_I, Tsaeda_embaba_III, Carneshim, Grandnain, Round_Sudan and Oval_Sudan while Group III contains Ajeba, (Figure 1). The grouping of accessions in clusters reflects the relative diversity of accessions which allows selection of accessions contained by each group as core collection [11]. The clustering is in agreement with the bi-plot clustering generated using the accessions vs. trait relationship (data not shown). The current cluster analysis shows that Yeha, Tsaeda_embaba_I, Tsaeda_embaba_II and Shahemanie_I are closely related accessions with more than $98 \%$ similarity. This can be attributed to the geographic source of the materials, although it is not applied to all accessions in different groups. Considering sources of the materials are farmers, it can be inferred that some of the accessions share the same background, although, farmers give them different names. For instance, accessions Yeha; Tsaeda_embaba_I; Tsaeda_embaba_II and Shashemanie_I. exhibited similar characteristics, yet they had different names. Most of the accessions are given names by farmers based on where they

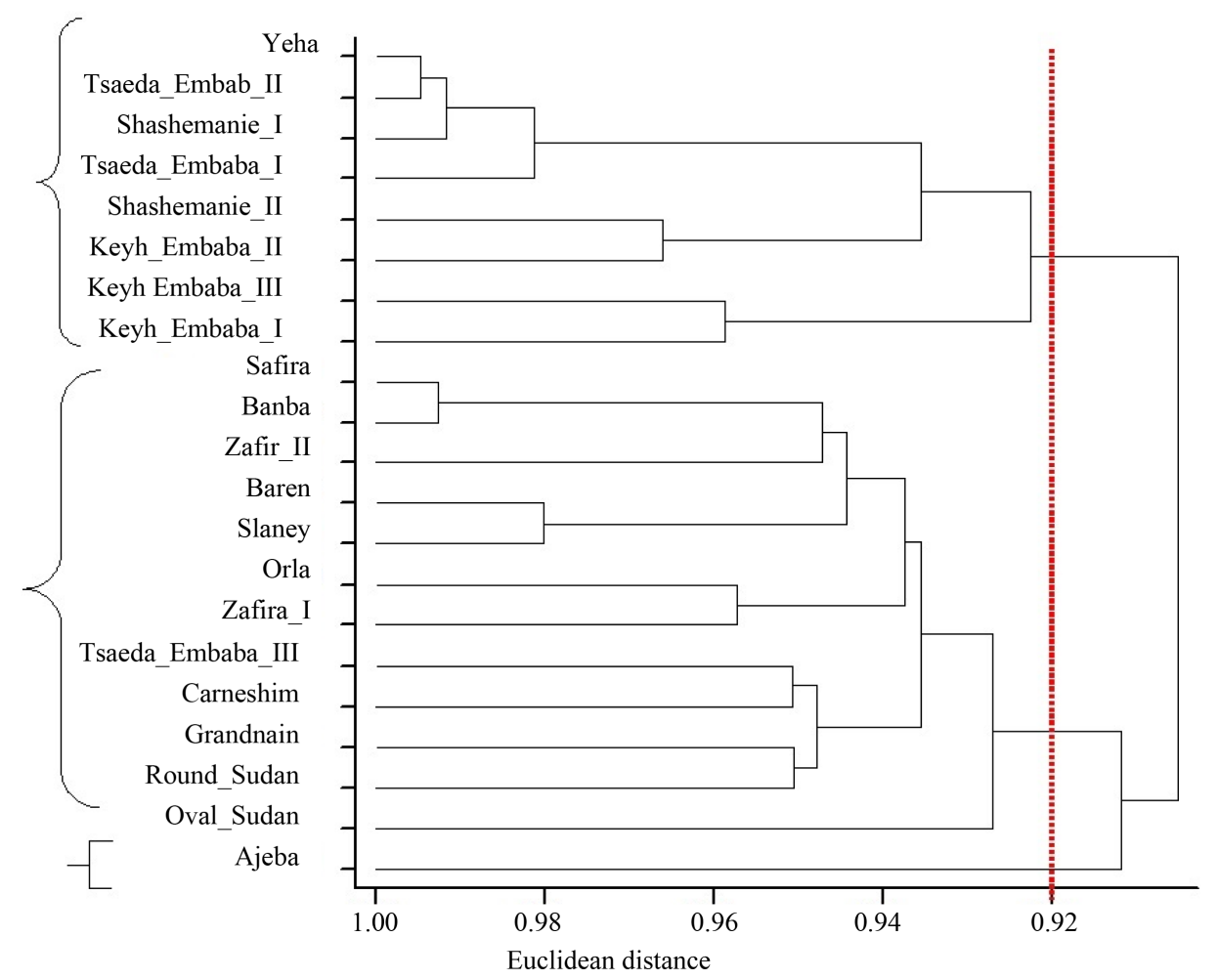

Figure 1. Dendrogram generated based on Unweighted Pair-Group Method with Arithmetic Averages (UPGMA) analysis using the Euclidean distances among the 21 potato accessions. 
were first introduced, for example, Shashemanie_I; while others are named based on their flower color, for example, Tsaeda_embaba with white flower colour. The current characterization thus confirms that they are either the same or closely related accessions that share the same background. Previously, [12] reported from their study that diverse system of sweet potato naming in Tanzania caused mixed up and duplication of cultivars as the same cultivars might be given different names in different localities.

At about 93\% similarity, Group I had joined another two more accessions (Shashemanie_II and Keyh_embaba_II), whereas at 92\% similarity level, two more accession had joined the group (Keyh_embaba_I and Keyh_embaba_III). These accessions, although they share the same name as given by the growers, have distinct variation from the other Keyh_embaba. Both produce red flower colour thus locally called (Keyh_embaba). They were collected from different locations but because of some similarities they were clustered in one group. Further study is required to actually declare that they share a similar genetic background or not.

Group II has a number of sub classes. Banba, Baren, Orla and Slaney (from NARI) mixed with Safira, Zafi$r a \_$I and Zafira_II sub clustered together at $94 \%$ similarity level. The first four were imported from Ireland by NARI for research purposes and hence they were expected to cluster together. However, it infers that they have some genetic similarity with Safira/Zafira groups. Further study is required to actually determine their similarity. On the other hand accessions Round_Sudan, Grandnain and Oval_Sudan are grouped together. These accessions were imported from neighboring country, Sudan, by individuals. The clustering analysis showed that there was some similarity (>93\%) between them. There is a probability that they share some background based on this preliminary result.

The locally known accession Carneshim clustered separately from other accessions grown in the same region such as Yeha, Keyh_embaba_I and Tsaeda_embaba (I \& II), but is related to Tsaedaembaba_III from a different region. This indicates that it does not share any background with the rest of the accessions growing in the same area (Sub-Zoba Serejeka) for many years. Another observation made during this cluster analysis is the name confusion between the accession called Zafira and Safira. The Zafira accession in Zoba Maekel was found to be different from the Zafira accession from Zoba Debub, indicating that although they share the same name they have no genetic similarity. On the other hand, the accession called Safira somehow showed some similarity $>94 \%$ with the accession Zafira collected from the same Zoba (Debub) explaining that they are either the same and/or share the same parental background. This result is realistic as they are from the same region although with different names. While the Keyh_embaba_II was found to be different from other Keyh_embaba accessions of "I" and "III" (Figure 1) which further indicated that although they shared the same flower colour, they explained more variation in the rest of the descriptors. According to [13], if accessions differed in relation to various characteristics or descriptors, they would be classified in distinct groups in the cluster analyses revealing their differences.

The finding of the current cluster analysis conforms to the PCA bi-plot scattering obtained (data no shown) where Yeha, Tsaeda_embaba_I, Tsaeda_embaba_II, Shahemanie_I, Keyh_embaba_II and Shashemanie_II grouped together, yet Keyh_embaba_I and Keyh_embaba_III fell in the same quadrant while others scatter in second and third quadrant. [14] obtained similar results and reported that principal component and cluster analysis yielded the same grouping of the accessions. The authors concluded that a good breeding program can be initiated by the selection of cultivars from the PC1 and PC2 and/or group with maximum positive deviation from the total mean.

It was noted from the cluster analysis that there was no strong relationship between the clustering groups and geographic sources of accessions. Similar results were reported by [11] where they found no sharp relationship between the clustering pattern of the potato accessions and their geographical sources. This can be ascribed to the free movement of accessions from one region to another within a country and the frequent illegal importation of accessions from neighbouring countries.

In order to record the value of each group in the cluster, mean deviation of each variable from the grand mean of the quantitative parameters was calculated (Table 2). This comparison of values will help to identify positive traits contained by each group in comparison with the total mean and thus select parent lines for crop improvement. Accordingly, Group I showed positive deviation to Flow DAP, No. PS, PH, and tuber set. Most of the accession in this group performed good except the two weakest links in this group (Keyh_embaba I and III). It should be noted that if these two inferior accessions are removed from the group the deviation becomes positive for most of the variables. Yet, Group II deviated positively in all the variables except for Flow DAP, No. PS, PH and tuber set. While Group III showed negative deviation except for Emer. DAP, No. PS and Tuber size. This is an accession preferred by most of the farmers owing to its early maturity (21 days earlier than the average) 
Table 2. Groups quantitative traits' mean and difference from the total mean in 21 potato cultivars.

\begin{tabular}{ccccccccccc}
\hline \multirow{2}{*}{ Group } & & $\begin{array}{c}\text { Emer. } \\
\text { DAP }\end{array}$ & $\begin{array}{c}\text { Flow } \\
\text { DAP }\end{array}$ & $\begin{array}{c}\text { Maturity } \\
\text { time }\end{array}$ & No. PS & PH & ST & T. set & T. size & T. wt \\
\hline \multirow{2}{*}{ Total } & Mean & 33.7 & 55.7 & 108.3 & 2.8 & 21.8 & 8.4 & 9.0 & 39.4 & 0.43 \\
& Difference & 0 & 0 & 0 & 0 & 0 & 0 & 0 & 0 & 0 \\
\multirow{2}{*}{ I } & Mean & 30.7 & 72.6 & 105.8 & 3.6 & 24.9 & 7.6 & 14.1 & 33.1 & 0.39 \\
& Differences & -3.0 & 16.9 & -2.5 & 1.8 & 3.1 & -0.8 & 5.1 & -6.3 & -0.04 \\
\multirow{2}{*}{ II } & Mean & 36.5 & 49.0 & 111.8 & 2.2 & 19.9 & 9.1 & 5.9 & 43.5 & 0.46 \\
& Difference & 2.8 & -6.7 & 3.5 & -0.6 & -1.9 & 0.7 & -3.1 & 4.1 & 0.03 \\
\multirow{2}{*}{ III } & Mean & 23.5 & 0 & 87.0 & 3.1 & 19.1 & 6.7 & 5.3 & 41.9 & 0.35 \\
& Difference & 10.2 & -55.7 & -21.3 & 0.3 & -2.7 & -1.7 & -3.7 & 2.5 & -0.08 \\
\hline
\end{tabular}

Emer. DAP = emergence day after planting; Flow DAP = flowering day after planting; No. PS = number of primary stem; PH = plant height; ST = stem thickness; T. set = tuber set; $\mathrm{T}$. size = tuber size and $\mathrm{T}$. wt = tuber weight.

although lower yield as determined by weight. It is, thus, inferred that accessions in Group I and II could be used as parent lines for breeding program depending on the required traits.

\section{Conclusion}

Plant characterization is of paramount importance before going for any breeding program and/or plant genetic resources conservation purposes. Cluster analysis, using morphological descriptors of the 21 accessions, generates three groups at $92 \%$ similarity level with a number of sub clusters. Group I consists of 8 accessions, Group II, 12 accessions and Group III, 1 accession. The clustering helpes to identify accessions that share the same characteristics and/or that are closely related and vice versa. The clustering further reveals that accessions with common name based on their flower colour may not necessarily contain the same genetic composition. It is observed that some accessions with different given names are similar sharing more than 99\% Euclidean similarity (eg. Yeha and Tsaeda_embaba_II). Likewise accessions collected from the same region are not necessarily similar. Mean deviation of variables for each group from the total mean indicates that Group II followed by Group I shows maximum deviation in most of the recorded yield related traits. Group II is characterized by having bigger tuber size with higher tuber weight but less tuber number per plant as compared to the other groups. Group I is characterized by higher number of primary stems and longer plant height resulting in higher tuber set but with smaller tuber size and lower tuber weight. This group is particularly affected by the presence of two inferior accessions (Keyh_embaba_I and Keyh_embaba_III). On the other hand, Group III is characterized by early maturity and lower yield. Group II followed by Group I accessions can, thus, be recommended for use as parental lines for a breeding program in Eritrea.

\section{Acknowledgements}

The authors wish to acknowledge the Japanese International Cooperation Agency (JICA) for funding the research work. We are also grateful to Hamelmalo Agricultural College (HAC) and Zoba Maekel Agricultural Research Unit for providing graciously land for the research.

\section{References}

[1] Biniam, M.G., Githiri, S.M., Tadesse, M. and Kasili, R.W. (2014) Diagnostic Survey on Potato Production Practices in Eritrea. ARPN Journal of Agricultural and Biological Science, 9, 444-453.

[2] Bereketsahay, T. (2000) Potato Production in Eritrea: Prospects for Future Development. Proceedings of the 5th Triennial Congress of African Potato Association, Kampala, 29 May-2 June 2000.

[3] FAOSTAT (2012) http://www.faostat.org/

[4] Kaguongo, W., Gildemacher, P., Demo, P., Wagoire, W., Kinyae, P., Andrade, J., Forbes, G., Fuglie, K. and Thiele, G. (2008) Framer Practices and Adoption of Improved Potato Varieties in Kenya and Uganda. Social Sciences Working 
Paper 2008-5, International Potato Center (CIP), Lima, 85 p.

[5] Biniam, M.G., Githiri, S.M., Tadesse, M. and Kasili, R.W. (2014) Potato Seed Supply, Marketing and Production Constraints in Eritrea. American Journal of Plant Sciences, 5, 3684-3693. http://dx.doi.org/10.4236/ajps.2014.524384

[6] Kandemir, N., Yilmaz, G., Karan, Y.B. and Borazan, D. (2010) Isolation of Different Accessions in "Baçiftlik Beyazi” Potato Landrace Using SSR Markers. Turkish Journal of Field Crops, 15, 84-88.

[7] Arslanoglu, F., Aytac, S. and OnerE, K. (2011) Morphological Characterization of the Local Potato (Solanum tuberosum L.) Genotypes Collected from the Eastern Black Sea Region of Turkey. African Journal of Biotechnology, 10, 922-932.

[8] Mondal, M.A.A., Hossain, M.M., Rasul, M.G. and Uddin, M. S. (2007) Genetic Diversity in Potato (Solanum tuberosum L.). Bangladesh Journal of Botany, 36, 121-125.

[9] Haydar, A., Ahmed, M.B., Hannan, M.M., Razvy, M.A., Mandal, M.A., Salahin, M., Karim, R. and Hossain, M. (2007) Analysis of Genetic Diversity in Some Potato Varieties Grown in Bangladesh. Middle-East Journal of Scientific Research, 2, 143-145.

[10] Huaman, Z., Williams, J.T., Salhuana, W. and Vincent, L. (1977) Descriptors for the Cultivated Potato and for the Maintenance and Distribution of Germplasm Collections. AGPE: IBPGR/77/32, International Board for Plant Genetic Resources, Rome.

[11] Lohani, M., Singh, D. and Singh, J.P. (2012) Genetic Diversity Assessment through Principal Component Analysis in Potato (Salamun tuberosun L.). Vegetable Science, 39, 207-209.

[12] Tairo, F., Mneney, E. and Kullaya, A. (2008) Morphological and Agronomical Characterization of Sweet Potato [Ipomoea batatas (L.) Lam.] Germplasm Collection from Tanzania. African Journal of Plant Science, 2, 77-85.

[13] Fongod, A.G.N., Mih, A.M. and Nkwatoh, T.N. (2012) Morphological and Agronomical Characterization of Different Accessions of Sweet Potatoes (Ipomoea batatas) in Cameroon. International Research Journal of Agricultural Science and Soil Science, 2, 234-245.

[14] Ahmadizadeh, M. and Felenji, H. (2011) Evaluating Diversity among Potato Cultivars Using Agro-Morphological and Yield Components in Fall Cultivation of Jiroft Area. American-Eurasian Journal of Agricultural \& Environmental Sciences, 11, 655-662. 